\title{
MODELS AND TARGETS FOR THE PRONUNCIATION OF ENGLISH IN VIETNAM AND SWEDEN \\ UNA CUNNINGHAM
}

\section{Introduction}

English has a unique position in the world. Not only is it the first language of what is still the only global superpower, although this might, of course, change in the near future, it is also the second language of millions of people in every part of the world. Never before have so many people shared a common language. Never before has it been possible to communicate across cultures and continents as effortlessly as now. The concurrent advent of electronic communication and the Internet means that we do not need to go to the inconvenience and expense of actually travelling from one part of the world to another before we are cast into a communicative situation with someone where we are required to use English with no warm-up time or acclimatization being possible. A person can step in out of the heat and bustle of the streets of Hanoi into an airconditioned Internet café or into their homes or workplaces where the honking of horns and the barking of dogs form a backdrop to the conversation via Skype or a video conferencing tool with a counterpart somewhere else, perhaps in Sweden, from the cool tranquillity of a forest cabin in a remote area of Dalarna. The juxtaposition of different physical spaces brings different cultural practices to the forefront. The transition in such a setting from a local language like Swedish or Vietnamese to English may be very sudden and feel quite strange. It is easier to communicate in another language if we have made a physical journey. In our new, globalised society we may be required to switch between languages rapidly and with no preparation. This places extreme requirements on our readiness for receiving English as spoken by speakers of any language. 


\section{Context}

\section{English in the expanding circle}

English is used for many purposes in the countries of what Kachru (1985) called the expanding circle, that is countries where English is not an official language. Graddol (2006:110) points out the failure of Kachru's three-circle model to capture the ways English works in our globalised world. Kachru himself (2005) proposes a move away from the nationbased three-circle model to instead look at the individual's English language proficiency, regardless of how, when or where the language was learned. Business and education are perhaps two of the most important domains where individual variation in the proficiency of speakers is prominent. In countries like Sweden and Vietnam, which have a national language which is little spoken outside the country it originates in, English has an important role as a lingua franca, to be used as soon as people who are not speakers of the local language are involved. Equally, as soon as a Vietnamese or Swedish speaker steps out of their country of origin, they will often turn to English, even if it is not the native language of their interlocutors. But it is significant to note that the English we are talking about here is a channel of communication, not a thing of beauty. The English used in such situations has no ambition to pass its speaker off as anything but a Swede or a Vietnamese person involved in intercultural communication. The use of English in such settings is instrumental, not integrative.

It follows from this that the English used in this kind of lingua franca situation, between speakers for whom English is not a first language at all, is subject to particular requirements. It needs to be clear and readily understood by people from various linguistic backgrounds. But Swedish and Vietnamese speakers may need English for many other purposes. Many of them may primarily want to relate to native speakers of English. Perhaps they plan to emigrate, or study abroad. In their work they may need to communicate regularly with clients or suppliers in the US or the UK. In such circumstances the Swedish or Vietnamese speaker might find it more useful to aspire to a pronunciation of English which makes it as easy as possible for native speakers of English to understand what is being said, or in particularly auspicious situations, where there is a major integrative motivation, to pass as a native speaker, or at least to sound as nearly native as is possible. But this is by no means an easy target to 
achieve and there are many reasons why it might not even be a desirable or appropriate target.

\section{English in Southeast Asia}

Southeast Asia is like a cross-section of the English-speaking world. In some contexts, English is a second language. The language has official status and is widely used for communication within countries. This is the case, for example, in Singapore and the Philippines. In other areas, English has no official status, such as in the expanding circle countries like Thailand, Vietnam, Indonesia. Kachru and Nelson (2006) account in detail for the historical background to the status of English in a number of Southeast Asian contexts.

Attempts have also been made to describe the linguistic characteristics of English in Southeast Asia. Kachru and Nelson (2006:188ff) offer a survey of studies of some phonological, lexical, syntactic and pragmatic features. It is difficult to find genuine regional characteristics of English in this area, given the variety of substrate or L1 languages involved. However, it is clear that when English is used within a country, local usages will develop. Some of these will be influenced by cultural considerations which may be common to a number of countries in the area, perhaps especially in matters of discourse practices.

\section{English in Vietnam}

So what kind of English is spoken in Vietnam? Is it English as a foreign language (EFL), making it one foreign language among others (French, Russian, Chinese, Korean are taught in Vietnam) where a native model and the target of becoming as close to nativelike as possible are givens. Or is it English as a Lingua Franca (ELF) or English as an International language (EIL), such as is used when, for example, Korean guests visit Hanoi. In these cases, being nativelike is not usually a good thing. A clear, fluent non-native speaker of English will likely be easier to understand than someone who has mastered the art of using the weak form. The English spoken in the streets and alleys of Hanoi cannot be considered a local variety of English. It is clearly Vietnamese, of varying intelligibility and comprehensibility even to Vietnamese listeners, taking some getting used to before the native or other non-Vietnamese ear becomes attuned.

English is not widely spoken in Vietnam. Any visitor who does not speak Vietnamese cannot rely on English for daily communication outside 
language faculties. The general public do not have access to information published or broadcast in English. The English language has no official status and Vietnam thus belongs firmly in Kachru's expanding circle. However, given English has the role of a language of international communication in the ASEAN countries, and native English speakers are not distinguished in any way from other non-Vietnamese speakers as interlocutors with whom one speaks English. English is the de facto default language for international communication in Vietnam. If the ambitious plans of the Vietnamese Minister of Education and Training come off, English-medium teaching will be introduced in many universitylevel programmes in science, business, tourism and technology. But there is a long way to go before English is widely spoken in Vietnam.

\section{English in Sweden}

The status of English in Sweden is very different from the status of English in Vietnam. Although English has no official status in Sweden, it fills in many respects the role of a second language in the country. Domain loss is a major concern for those dealing with the welfare, maintenance and development of the Swedish language. Whole areas of endeavour, such as tertiary education in a growing number of subjects, are being conducted wholly or partly in English instead of Swedish. Tourists and international students in Sweden find that they manage very well in their daily superficial contact with Swedish society without ever learning much Swedish. The fact that many Swedes do not, in fact, speak much English comes as a surprise to many. In fact I met a young woman from the UK at the end of her stay in Uppsala who was convinced that she had just spent a month in "the English-speaking part of Sweden". There is, of course, no such part, but Swedes under 60 years of age are generally able to understand basic English and many are willing and able to speak English as and when the need or opportunity presents itself. English was introduced as a compulsory subject at school in the 1960s. Sweden is one of the richer nations and Swedes travel abroad in huge numbers. They expect to use English wherever they go outside Sweden, in much the same manner as the inner circle monolingual English speaker. 


\section{Listeners}

\section{Listener expectations}

Now it may be considered unfortunate that the needs and preferences of native speakers of English are not entirely congruent with those of nonnative speakers. Any language will have its peculiarities in matters such as how to distinguish between its vowels and consonants, such that the main difference for English speakers between $/ \mathrm{p} /$ and $/ \mathrm{b} /$ is not whether or not the vocal folds are vibrating during the stop phase of the sound, but rather at exactly what point the voice onset occurs in a word like pat compared to bat relative to the release of the stop (cf. e.g. Cruttenden 2008). This is not the way it works in all languages, Speakers of a language are not generally aware of the way they signal stop voicing in their own language, and they are more than likely to transfer their familiar native way of making the distinction to their English. This means that Vietnamese or Swedish speakers will be transmitting Vietnamese or Swedish cues about consonant voicing in the English they speak. Unless the recipient is a native speaker of the same language, perception of the intended consonant is a hit-andmiss affair. Native speakers of English are particularly intolerant of this and particularly unreceptive to the wrong cues. But it has been found (Bradlow \& Bent 2006) that even native speakers of English can learn to listen more flexibly and that they can become accustomed to an accent.

\section{Intelligibility}

So, what we are actually talking about here is whether the Vietnamese learners are better served by EFL or ELF (or perhaps EIL or a World English) in the senses laid out by Jenkins (2002) among others. Jenkins (2002) described a "Lingua Franca Core" for pronunciation targets. Intelligibility is the aim here and native speaker targets are not relevant where they do not coincide with the requirements of intelligibility. Berns (2008) examines the relationship between World Englishes, ELF and intelligibility. She concludes that, while ELF research refers to World Englishes research, there are important differences between the two movements, and she claims that "identification of core features of nonnative speech in an effort to control language performance and guarantee the success of this performance - even if the result is the overthrow of the tyrannical native speaker - is simply meeting the new boss who's the same 
as the old boss, or the hegemony of the old with the hegemony of the new"(Berns 2008:333).

In what Kachru (2008:293) calls "the Smith paradigm for intelligibility" (Smith 1978) there are three stages: intelligibility, comprehensibility and interpretability. Berns (2008:328) compares and contrasts Jenkins' (2006a) writing on intelligibility with Smith's. She suggests that Jenkins' concepts accent, propositional content, and pragmatic sense in the sentence "speakers need to be confident that their accents will not prevent them from understanding the propositional content of one another's utterances (even if they then go on to misinterpret each other in a pragmatic sense)" (Jenkins 2006a:36) might correspond to Smith's intelligibility, comprehensibility and interpretability. Jenkins (2006b:139) also addresses the relationship between the ELF, EFL and SLA traditions and compares outer circle nativized varieties and expanding circle lingua franca varieties. She claims that, as native speakers are the "target interlocutors" in neither case, they are not a relevant reference point.

Iser (1978) developed the concept of the "implied reader" who is the imagined recipient of an author's expression. According to Iser (1978:34), the implied reader "embodies all those predispositions necessary for a literary work to exercise its effect - predispositions laid down, not by an empirical outside reality, but by the text itself." Here we can perhaps consider the "implied interlocutor" to be the learner's conversational partner. In traditional EFL, the implied interlocutor is the native speaker of English. This is no longer a satisfactory model. Learners in modern Vietnam may never have occasion to converse with native speakers of English. This is not what they need to be schooled to do. The English they speak will be required to be intelligible and comprehensible to speakers of any and every language, but may be used more often with speakers of other Asian languages.

The interlocutor for Swedish learners of English is as likely to be a speaker of Finnish, Dutch or Italian as a native speaker of English, and in fact Swedish speakers, given the low numbers of Swedish speakers in the world, will often try English before Swedish with anyone who gives the slightest impression of not being Swedish. In places with many international visitors, such as youth hostels or student residences, Swedes report going for weeks speaking English with their neighbours before realising that they share Swedish as a native language. Nonetheless, the implied interlocutor in Swedish models of English language education has long been the native speaker. This has tacitly changed now and the explicit target for the pronunciation of English in the current curriculum for 
Swedish schools (Skolverket 2000) makes no mention of native models or targets, stipulating that students strive for clear and intelligible

pronunciation. In fact, this is also the case for the Swedish curricula for foreign languages other than English. In no case is the student explicitly encouraged to aim at native-like use of the target language. Thus, the explicitly expressed target for the learning of English as a foreign language in Swedish upper secondary schools is in fact intelligibility.

\section{Targets}

\section{Student targets}

Student targets may not always coincide with the targets of the curriculum. Smith (1978:11) wrote "Today few people are willing to sound like native English speakers or to identify with their culture as is typically required in the second language situations". While this is true in many parts of the world, and may well have been the case in earlier periods of Vietnam's history, there do not appear to be any strong feelings against native accents of English at present. Unlike the situation for English speakers in outer circle contexts in South Asia, or other regions of Southeast Asia, where there are regional varieties which serve as student targets and to some degree models, in Vietnam the status of the native speaker model and near-nativeness as the ultimate target are unquestioned. In Sweden, however, many of our students adopt Smith's line and reject nearnativeness as a target, claiming the right to sound Swedish in English. This would appear to be a feature more generally associated with inner and outer circle speakers who can make reference to a local variety of English, which is not the case for English in Sweden.

Students are, however, not a homogenous mass. Individual students will see the matter of targets differently. This will depend on a number of factors. Firstly, the student's ability or aptitude for language and for imitating sounds will be important. Ambition will also be significant. A more motivated learner will be able to give the language learning project more effort. How motivated the learner is will depend on his or her needs. Will the language be used for work, or for study abroad? There is really no way to know in advance what uses a learner will find for their language skills in the future. It is hardly possible to assign learners to different groups at a young age according to which set of targets is to be theirs. Some students are able to use their language outside school as well as at 
school. For those learners different kinds of input will be available, and they will more easily gain fluency.

Teacher targets may be different from student targets. Teachers are concerned about their students' progress, but may also have other concerns, such as course throughput, and using their contact hours to best benefit the students while not causing an unreasonable teaching load.

There are also national, or governmental targets to be addressed. Kirkpatrick, Deterding and Wong (2008) report that several ministries of education in East Asia insist on native models of English as models for teaching while sometimes expressly forbidding the use of local varieties as models. Having a well-educated population is the hallmark of a prosperous nation, and English language skills are a large part of a nation's international education impression. So for reasons of national pride, schools may be encouraged to invest time and resources to ensure that students develop as high proficiency as is feasible. The curriculum and syllabi will be set with this in mind. National pride is one side of the coin - the other is national needs. If the country has use of a population with good English-language skills, there is a point to earmarking resources to ensuring that young people spend enough time and energy learning English. Of course there may be a price to pay if national interests are not well served by a population who are able to join in the global babble on the Internet. Citizens with access to the international community are able to find information and discuss their concerns with people in other cultures. A common language is an important tool for democracy and the empowerment of the individual.

In Sweden, little or no time is devoted to the teaching of English pronunciation before university level classes in English phonetics which often have an element of pronunciation training. It is assumed that students hear enough English around them, through films, music and media and that this will influence their pronunciation. It does, of course, but they do not speak English like native speakers. In many other countries, including Poland and Vietnam, pronunciation is actively taught. Like any other aspect of language learning (grammar, vocabulary) it is difficult to automatise what is learned intellectually. But the effect of pronunciation teaching is to raise students' awareness of the difference between English sounds, and the difference between these and the sounds of L1. After that the learner needs to actually use the new sounds. 


\section{Targets for pronunciation}

Targets for ultimate achievement in the pronunciation of English will, thus, vary from individual to individual and from setting to setting. And, of course, the conditions and probability for success in actually achieving the target also vary. We can consider the targets regarding ultimate achievement in English pronunciation as falling into one of two categories. Either the speaker aspires to pronounce English is a way that is as close as possible to a native variety of English, or they aspire to pronounce English in such a way as to be clear and intelligible to as many people as possible, both those who have English as their first or only language and those for whom English is an additional or second language. This is the crux of the matter, and much has been written about the choice between these positions. Jenkins (2007:141) reports that non-native speaker teachers of English teachers are unwilling to consider any non-native norm or to "disassociate notions of correctness from 'nativeness' and to assess intelligibility and acceptability from anything but an NS standpoint".

Once the model is decided, it is possible to set a target for the learner. The choice of target depends on a number of factors. Firstly, who will the student interact with? If extensive interaction with native speakers of English in an English-speaking country is envisaged, such as is the case for immigrants to English-speaking countries, there is obviously considerable integrative motivation. Such learners may want to sound as much like the native speakers they associate with as is possible to facilitate their integration into mainstream society.

Alternatively, the immigrant-learner may prefer to retain as much of the characteristics of their L1-influenced accent of English as is consistent with good intelligibility. This may be important in many situations where immigrants interact with others who share their linguistic and cultural background such that there can be considerable covert prestige in the subculture of the immigrant group associated with a characteristic accent. Even in cases where there is no L1 subculture to associate with, too close an approximation to the native pronunciations of the majority population might have consequences for the individual's expression of identity. In such cases a characteristic accent might be important for the personal integrity of the immigrant, who does not seek to pass themselves off as something they are not. A non-native accent can, of course, be a useful indication that the speaker cannot be assumed to have the cultural competence expected of a native speaker of his or her age.

For those who are not immigrants, such as is generally the situation for learners in Sweden or Vietnam, integrative motivation is not a factor. 
Instrumental motivation is likely to be more important. Such learners will need to meet the grading criteria set out in the syllabi they follow, or need to impress potential employers sufficiently, or need to have a level of English that makes it possible for them to function in their position. They may need to meet native and non-native speakers of English in their work, and their English pronunciation will reflect on the reputation of their employer. Unintelligible or otherwise strongly accented speech will most likely not be viewed favourably by employers who may want to make a good impression on clients. There is a considerable loss of dignity associated with a strong foreign accent (Cunningham-Andersson \& Engstrand 1990). This means that the prime concern as regards learner targets must be to ensure that intelligibility is not a problem.

Jenkins (2002) offers a list of detailed pronunciation targets intended to ensure maximum intelligibility to listeners with many L1s. Once intelligibility is ensured, it is possible to pay attention to the aesthetics of English pronunciation. It is possible for a learner to aspire to a pronunciation that is judged as acceptable, or attractive (cute, sexy, childish) by native listeners. Studies of attitudes to accents (e.g. Cunningham-Andersson \& Engstrand 1990) are able to produce quite clear results. But the question is, does a business person trying to clinch a multimillion deal, or a manager having to lay off workers really want to come across as cute or sexy in all kinds of situations? Of course the learner needs to project the same range of personality features in English as in his or her native language.

Now it may often be the case that the learner is required to aspire to a native-like pronunciation of English by his or her teacher and the syllabus being followed. The reasoning behind this position is very logical. Since native speakers enjoy higher status than non-native speakers, it can be argued that any target short of nativelikeness is doing the learner a disservice. The learner must be afforded the opportunity to acquire a nativelike accent. To this end, millions of learners in every continent struggle to master weak forms and the nuances of vowel differentiation in English. And of course, there are those learners who do manage to achieve a pronunciation close to RP or General American, but it is exceedingly rare for this to happen without an extended period in an environment where this accent is widely used. Extremely few learners in Sweden or Poland or Japan or Vietnam reach such a target. Instead they end up with as strong a Swedish, Polish, Japanese or Vietnamese accent as their peers who have other targets.

In some syllabi students are even required to be consistent in their pronunciation. They may be required to choose British or American 
pronunciation or may have one or the other set as their model and target, and will often then be required to be consistent to the pronunciation norms of that accent. Mixing in features of the other variety will then be penalised. The difference between those who aspire to an RP accent and those who inspire to maximum intelligibility can be illustrated by the example of the TRAP vowel (to use the word-class terminology introduced by Wells 1982). In Swedish and Vietnamese there is a vowel which is quite close to the [0] vowel used in RP in words like dress. These languages also have a low front or central vowel [a] (Engstrand 2004, Nguyen 1970 respectively), as indeed does Polish (Jassem 2003). When it comes to attempting the TRAP vowel (elsewhere called the ash-vowel, e.g. Szpyra-Kozlowska 2008 on Polish learners of English), the speakers are faced with a choice between learning this vowel as a new vowel category (Flege, Schirru \& Mackay 2003) or of seeing it as similar to one of the vowels they have in their system ([?] $]$ or [a]). There is a tendency for learners who are forced to attempt to approach the RP value of the TRAP vowel to be unable to distinguish it from their own L1 [?]. This means that they are unable to distinguish between, for example, bet and bat. For the purpose of intelligibility it would in fact be much more appropriate for them to have settled for their [a] vowel. There is no RP vowel nearby for this to be confused with, and this kind of [a] pronunciation is actually used by many native speakers of English, for example in Ireland.

The case of the $a s h$-vowel is an illustration of the downside of insisting on a native model rather than looking at intelligibility first. A failure to reach targets of nativelikeness when using a native model can lead to great problems with intelligibility. Success in reaching the target is, of course, richly rewarded. It can be argued that a teacher who does not set learners the target of aspiring to native-like pronunciation is doing learners a great disservice. In most endeavours it is better to come some way towards a target than not at all, but the near-nativeness target is reached by very few. The efforts made by the learner may well end up making their speech unintelligible.

\section{Attitudes to non-native Englishes}

\section{Liberation linguistics}

The arguments against native models for learners of English who are not immigrants to the inner circle countries are not only concerned with 
considerations of intelligibility, but also with power and ideology. The alternative model would be a fluent, highly proficient non-native speaker of Standard English who shares the learners' first language. And here Quirk and Kachru are at loggerheads. Kachru (1992:61) argues that external (British and American) models may be linguistically and sociolinguistically inappropriate for learners in other cultures because they have no relevance to the region the learners are living and working in, and they reflect British and American culture.

Quirk (1990:9) objects to the prospect of learners being encouraged to have anything but Standard English as a model or target. He writes: "It is neither liberal nor liberating to permit learners to settle for lower standards than the best, and it is a travesty of liberalism to tolerate low standards which will lock the least fortunate into the least rewarding careers." Quirk has been widely criticised for this position (e.g. Kachru 1991), but his views are anyway held by many educators and many learners.

The International TESOL organisation, the professional association for English language educators writes in a position statement (TESOL 2008): "With English being taught globally for very diverse purposes, a singular or monolithic approach to the modeling of English is no longer tenable. [...] In terms of language teaching, TESOL does not advocate one standard or variety of English over another. Rather, TESOL urges English language teachers to make informed decisions at local, regional, and/or national levels, taking into account the purposes and contexts of use that are most relevant to their learners." So, what is an appropriate model for learners in Vietnam then, such as could be represented in teaching materials? The alternative to native models is a non-native model, such as the English spoken by fluent Vietnamese speakers of English. The advantages of such a choice of model are that it is relevant to the Vietnamese learner of English; it is not associated with a foreign culture, and it facilitates the formation of meaningful targets for the learners. But this model may be unpalatable to many learners.

If a native model is chosen for the teaching of English pronunciation, which native variety is appropriate? Received Pronunciation (RP) is the standard codified British pronunciation, yet it is spoken by a tiny minority of the population of England (Macaulay 1988). Macaulay (1988:115) writes, "It would be better for everyone if linguists, phoneticians, and teachers overcame their fascination with the accent of an élite minority and concerned themselves more with the speech of the majority of the population." The choice of RP as a model is particularly problematic as this accent carries with it a good deal of sociocultural baggage, being traditionally picked up by those who attend expensive private schools. Do 
the English learners of the world really need to model their pronunciation on the speech patterns of the English upper classes and those who aspire to belong to them? Sounding as though one belongs to a social and economic elite may alienate more native listeners than it impresses. General American (GA) is an alternative model which is also the accent which forms the basis not only of a good deal of teaching materials, but also of many millions of native speakers of English. A potential problem with this accent in many parts of the world is that learners may not find it politically acceptable to aspire to an American accent. Perhaps a third option, at least in Southeast Asia, is to have Australian English as a model for pronunciation.

Kachru (1992) discusses the development of non-native models of English as being an attitudinal issue in essence. Even though non-native varieties may be widely used and "functionally valuable" the "accent bar" separates the native speakers from the non native speakers, even in the view of fellow non-native speakers. The non-native model is not codified or recognised by many teachers and learners as a norm. Teaching materials are not contextualised into the local environment. Kachru calls for a disassociation of English from its colonial past, and from Western culture and values.

\section{Deficit variety}

The notion of the learner as an imperfect or deficient native speaker is inherent to the discussion of the choice of a native model. Kachru (1991), in response to the insistence by Quirk (1990) on the superiority of native models, writes that "what is 'deficit linguistics in one context may be a matter of 'difference' which is based on vital sociolinguistic realities of identity, creativity and linguistic and cultural contact in another context". Local varieties might be a more appropriate model given these factors. Graddol (2006:83) points out that there is an ideological position intrinsic to the use of native models setting the learner up for failure as few learners ever come close to the native model they are set to aspire to. Li (2007:11), talking about English in China and Hong Kong, claims by the same token that "a curriculum informed by a deficit model (by measuring learner performance using the yardstick of native speaker-based standards) is by its very nature disempowering". At the same time, Kirkpatrik, Deterding and Wong (2008) point out that Hong Kong English is in fact widely intelligible. 


\section{Models}

\section{Choice of model}

Derbel \& Richards (2007) write that "there remains among English language professionals a pronounced tendency — here, most crucially, among native speakers of English - to look upon English as belonging to users of the inner circle and upon native speakers and their world views as reference points for all 'other' speakers of English". They go on to point out that it is not only in the inner circle that the supremacy of the inner circle varieties is held. Even in universities in the outer and expanding circles, non-native English may not be dealt with at all in undergraduate programmes in English.

Depending on the targets being aimed at or imposed on the learner of English, a model can be chosen. The first decision to be made is whether the model should represent an external standard of some kind, that is a native standard accent of English, or whether a non-native model is appropriate. There are some compelling arguments in favour of native models.

Firstly, just as the standard dialects Standard British English and Standard American English (which are not actually all that different from each other, although each can be uttered with a great many different accents) are well described and codified as to their grammar and lexis, the main standard accents of English, such as Received Pronunciation (RP) for British English, and General American (GenAm) in the United States, are well described in dictionaries and other reference sources as well as being the basis for a good deal of the research into the pronunciation of English that has been carried out to date.

Quirk (1990) rails against "the linguistic ethos that one English is as good as another" and is countered by Kachru (1991) who describes Quirk's position as deficit linguistics. Kachru asks "can international codification be applied to a language which has over 700 million users across the globe?" and suggests that it cannot. But not all English language teaching is aimed at international intelligibility even if the model is a local one. Singh (1987) describes how English can be taught in an Indian context with no concessions being made to native speaker norms or culture.

Another argument for upholding the standard pronunciations as models for learners of English is to maintain the status of English as a global 
channel of communication. If local models alone are aspired to by learners and offered by teachers there is a risk that English spoken in different nonnative settings will become progressively more different from the native standards and will develop along its own local path, leading to the eventual disintegration of English into a family of local, mutually incomprehensible vernaculars (Crystal 2003) as happened with Latin. But given the multitude of sources of English available to learners it is unlikely that they will only be exposed to a local English model. The global babble is loud and naturally compelling for our young people.

Outside Kachru's inner circle, that is countries where English is widely spoken as a first or native language, English is not, by definition, used for all functions in society. This means that there are gaps in the English of many non-inner circle speakers, corresponding to the domains for which English is not a natural language to use. This may mean that these varieties of English are less appropriate as models than the standard inner circle models, which have wide usage patterns.

\section{The role of the native speaker}

Phillipson (1992:194) describes a position where the "native speaker serves as the model who can personify the native speaker abstracted and reified". He explains this overreliance on the native speaker as the native speaker fallacy. Native speakers of English often have no experience of foreign language learning, and unless they have qualified teacher status and have studied English as an academic subject they have little to bring to the learner other than a model which they are not equipped to analyse. Phillipson (1992:195) accounts for the native speaker fallacy as dating from a time when language teaching was the same thing as culture teaching. In this case the native speaker is not only a linguistic model, but also a representative of the culture. Graddol (2006:114ff) refers to the native speaker problem, claiming that the native speaker model has outlived its usefulness for learners now that many descriptions of English are based on corpus research.

Native speaker volunteers (usually not qualified as language teachers) can be found in Vietnam, although they are not available to all learners. The opportunities for Vietnamese learners to hear English spoken by people whose first language is not Vietnamese are limited. There is little English-language broadcasting on Vietnamese television, although foreign channels like the BBC and CNN are available for those who can afford them. This results in an eagerness on the part of many Vietnamese learners 
to approach any lone non-Asians they see in public places to attempt to engage them in conversation. The possibilities for misinterpreting such approaches are obvious and unfortunate. With the advent of widely available Internet access, many more sources of English are available through webradio and dedicated language learning sites.

The position in Sweden is very different. English is heard intermittently in many contexts. Television is not dubbed and many British, American, Canadian and Australian programmes are broadcast. Films are also generally screened in the original language (the exception being films aimed at preliterate children. Most of the music sold and on the air in Sweden is sung in English, even when produced by Swedish artists. By the time children begin studying English in school (varyingly between the age of 7 and 10) many already have a considerable vocabulary.

\section{Non-native models}

Jenkins (2002) proposes a radically different approach to the matter. She distinguishes very clearly between English as a Foreign Language (EFL), aimed in principle at communication with native speakers, and English as an International Language (EIL) or English as a Lingua France (ELF). In the former case, she claims, the use of a native model is appropriate and logical for English as for any other language. In the cases of EIL and ELF she argues that a native model is not appropriate since native speakers do not speak in a way that is maximally intelligible to as many native and non-native listeners as possible. Instead she identifies a number of specific pronunciation targets for learners of English and discourages attention being paid to such features of native pronunciation as weak forms, since they actually make the speech more difficult for non-native listeners to understand, and interdental fricatives since the enormous effort required to learn the pronunciation of these typologically unusual sounds is not motivated. She argues that, since many native speakers also substitute other sounds (often /f/ and /v/) there is no problem with non-native speakers doing the same. Of course, this approach has sparked storms of controversy (cf. e.g. Szpyra-Kozlowska 2008 for a discussion of the Polish response).

So what kind of non-native model can be appropriate? The obvious candidate here is the proficient non-native speaker who shares the first language of the learners. The advantages are that the model is the basis for realistic targets. It is reasonable for the learner to base their pronunciation 
on such a model. But what if the learner has a different target? What if they, for whatever reason, might aspire to sound less accented than their teacher, more nativelike or in some other way different? Then their options have been limited by being offered such a model. Another solution might be for the learner to be exposed to a variety of models, representing speakers with a range of native languages, including native speakers of English from different countries. Some English teaching materials are aimed at the EIL market and will provide the learner with English spoken in many parts of the world. This is, of course, democratic, and should lead to a variety with very little to identify it geographically. It will likely mean that the learner will have features of many Englishes in their pronunciations alongside the substrate of their first language(s). Ideally, such English should be reasonably intelligible to a wide range of listeners.

Graddol (2006:115) looks at alternative models, citing the use in China in the 1990s of Belgian teachers of English who were valued because of their experience of bilingual education, and the suggestion that "the tools and idiom of Indian English" might be more appropriate for Cambodia, Laos, Burma and Vietnam than native models.

\section{Conclusion}

The learner needs to be exposed to a variety of Englishes to make sure that he or she is able to understand as many different kind of speakers as possible. But when it comes to a model or models for the learners' own pronunciation there are choices. British, American, Australian, fluent nonnative speaker of English-it is a matter of taste and perhaps politics. As regards pronunciation targets, however, the position is another.

Intelligibility must come first. Without that, communication will fail. If the model needs to be tweaked to enhance intelligibility as in the case of the ash-vowel mentioned above, so be it. For the minority who have the desire or need to "improve" their pronunciation (making it very clear we are talking about improvements that may impair intelligibility) there are opportunities to do so, particularly in English-speaking countries. An unintelligible pronunciation that contains many features of native accents of English is less than useless.

\section{References}


Berns, M. 2008. World Englishes, English as a lingua franca, and intelligibility. World Englishes 27 (3-4), 327-334.

Bradlow, A. R. \& Bent, T. 2008. Perceptual adaptation to non-native speech. Cognition 106, 707-729.

Cruttenden, A. 2008. Gimson's Pronunciation of English. London: Hodder Education.

Crystal, D. 2003. English as a Global Language. 2nd ed. Cambridge: Cambridge University Press

Cunningham-Andersson, U. \& Engstrand, O. 1990. Native speaker reactions to non-native speech. In J. Leather and A. James (eds) New Sounds 90, Proceedings of the 1990 Amsterdam Symposium on the Acquisition of Second Language Speech (University of Amsterdam, 912 April 1990), 1-13.

Derbel, F. and Richards, A. R. 2007. Infusing a postcolonial component into English language teacher education curricula for a global century. Radical Pedagogy 9:1. [Accessed at http://radicalpedagogy.icaap.org/content/issue9_1/derbel_richards.html on 26 October 2008].

Engstrand, O. 2004. Fonetikens Grunder. Lund: Studentlitteratur.

Flege, J.E., Schirru, C., MacKay, I.R.A. 2003. Interaction between the native and second language phonetic subsystems. Speech Communication 40, 467-491.

Graddol, D. 2006. English Next. British Council. [Accessed at http://www.britishcouncil.org/learning-research-english-next.pdf on 28 October 2008].

Iser, W. 1987. The Implied Reader: Patterns of Communication in Prose Fiction from Bunyan to Beckett. Baltimore, Md.: Johns Hopkins University Press

Jassem, W. 2003. Polish. Journal of the International Phonetic Association 33 (1), 103-107.

Jenkins, J. 2000. The Phonology of English as an International Language. Oxford: Oxford University Press

Jenkins, J. 2002. A sociolinguistically based, empirically researched pronunciation syllabus for English as an International Language. Applied Linguistics 23 (1), 83-103.

Jenkins, J. 2006a. Current perspectives on teaching World English and English as a Lingua Franca. TESOL Journal 40, 157-81.

Jenkins, J. 2006b. Points of view and blind spots: ELF and SLA. International Journal of Applied Linguistics 16 (2), 137-162.

Jenkins, J. 2007. English as a Lingua Franca: Attitude and Identity. Oxford : Oxford University Press. 
Kachru, B.B. 1985. Standards, codification and sociolinguistic realism:

The English language in the outer circle. In English in the World:

Teaching and Learning the Language and Literatures. In: R. Quirk and

H. Widdowson (eds) Cambridge: Cambridge University Press and The British Council, 11-30.

Kachru, B.B. 1991. Liberation linguistics and the Quirk Concern. English Today 25, 3-13.

Kachru, B.B. 1992. Models for non-native Englishes. In B. Kachru (ed.)

The Other Tongue. English Across Cultures. $2^{\text {nd }}$ ed. Urbana, IL:

University of Illinois Press, 48-74.

Kachru, B.B. 2005. Asian Englishes: Beyond the Canon. Hong Kong: Hong Kong University Press.

Kachru, B.B. 2008. The first step: the Smith paradigm for intelligibility in world Englishes. World Englishes 27, 293-296.

Kachru ,Y. \& Nelson, C. 2006. World Englishes in Asian contexts. Hong Kong: Hong Kong University Press.

Kirkpatrick, A., Deterding, D., and Wong, J. 2008. The international intelligibility of Hong Kong English. World Englishes 27 (3-4), 359377.

Li, D. 2007. Researching and teaching China and Hong Kong English. English Today 23:3\&4, 11-17.

Macaulay, R. 1988. RP R.I.P. Applied Linguistics 9 (2), 115-124.

Nguyen, D. L. 1970. A contrastive phonological analysis of English and

Vietnamese. Pacific Linguistics Series, no. 8). Canberra: Australian

National University.

Phillipson, R. H. L. 1992. Linguistic Imperialism. Oxford: Oxford University Press.

Quirk, R. 1990. Language varieties and standard language. English Today 21, 3-10.

Singh, F. 1987. Power and politics in the context of grammar books: The example of India. World Englishes 6 (3), 195-9.

Smith, L. E. 1978. Some distinctive features of EIIL vs ESOL in English language education. Cultural Learning Institute Report 5 (3), 5-11.

Smith, L. E. \& Nelson, C. L. 2006. World Englishes and issues of intelligibility. In: B.B. Kachru, Y. Kachru and C.L. Nelson (eds) The Handbook of World Englishes. Maldon, MA.: Blackwell.

Skolverket 2000. English A syllabus. [Accessed 2 February 2009 at http://www3.skolverket.se/ki03/info.aspx?sprak=EN\&id=EN\&skolfor $\underline{m}=21 \& a r=0809$ \&infotyp $=171$.

Szpyra-Kozlowska, J. 2008. English Pronunciation Pedagogy in Poland Achievements, Failures and Future Prospects. In E. Waniek-Klimczak 
(ed) Issues in Accents of English. Newcastle upon Tyne: Cambridge Scholars Publishing, 212-234.

TESOL 2008. Position Statement on English as a Global Language (April 2008; PDF). [Accessed at http://www.tesol.org/s_tesol/bin.asp?CID=32\&DID=10884\&DOC=FI LE.PDF on 28 October 2008].

Wells, J. C. 1982. Accents of English Vol. I-III. Cambridge: Cambridge University Press. 